\title{
Investment in Information and Communication Technologies in the Irish Education Sector
}

\author{
Clare McInerney, Mike Hinchey, and Eamonn McQuade \\ Lero- the Irish Software Engineering Research Centre \\ University of Limerick, Ireland \\ \{clare.mcinerney, mike.hinchey, eamonn.mcquade\} alero.ie
}

\begin{abstract}
Ireland's economy has experienced phenomenal growth over the last ten years, in particular in the ICT sector. With today's rising global competition, Ireland faces the challenge of sustaining this growth, particularly in the software sector. A core component of this challenge is to produce a steady stream of qualified graduates in the ICT area. Funded by the Irish government, Lero- the Irish Software Engineering Research Centre has begun two educational initiatives to address this issue: the establishment of the Lero Graduate School in Software Engineering (LGSSE) and the Lero Education and Outreach Programme. This paper describes both initiatives in detail and their uniqueness in the Irish context.
\end{abstract}

Keywords: ICT, Education, Outreach, LGSSE, Networking and Collaborations, Informatics, Programming and Problem Solving.

\section{Introduction}

Ireland is one of the world's largest exporters of software. This sector is worth €12 billion per annum to the Irish economy. There are more than 800 software companies employing 32,000 people in the country ${ }^{1}$. A key action outlined in the government's Strategy for Science Technology and Innovation is to "double the number of PhDs by 2013 "2. This strategy paper also acknowledges that research programmes in innovative economies are underpinned by graduate schools. The success of the software industry and strong research foundations in Ireland along with government strategy for science, technology and innovation inspired the successful establishment in 2008 of the first of the educational initiatives undertaken by Lero: the Lero Graduate School in Software Engineering.

A full time Education and Outreach Manager was hired in July 2007 to run the Lero Education and Outreach programme. Lero is a Centre for Science, Engineering and Technology (CSET). Science Foundation Ireland (SFI), the funding body for 7 CSETs in Ireland in areas of ICT and biotechnology, mandates the establishment of Education and Outreach Programmes by CSETs.

\footnotetext{
${ }^{1} \mathrm{http} / / / \mathrm{www}$. idaireland.com

${ }^{2}$ http://www.entemp.ie/publications/science/2006/sciencestrategy.pdf
} 
The goal of such programmes is to encourage an interest in science and technology in the education sectors. Since the "dot com" bubble burst in 2001, following global trends, Ireland has witnessed significant decreases in the number of students completing degrees in Computing and related areas. The Lero Education and Outreach Manager has been working to address this problem.

\section{LGSSE}

In order to create and sustain a knowledge-based economy and conduct world class research, Ireland aims to double the number of PhD students by 2013 to around 120 in computer science [4]. LGSSE is contributing to this national governmental goal, enrolling the first batch of students in September 2008.

These students are embarking on a 4-year structured PhD program at University of Limerick, Dublin City University, Trinity College Dublin and University College Dublin, the four partners in the Lero consortium of universities. LGSSE is funded by the Higher Education Authority (HEA) Program for Research in Third Level Institutions Cycle 4 (PRTLI 4).

\subsection{Rationale for the Programme}

The LGSSE academic programme was proposed to deal with a number of key issues facing high quality graduates in Ireland today. These issues include:

- Little uniformity in time-scales for completion of postgraduate studies. There is little by way of widely-accepted milestones to monitor progress.

- Some of the current models in Irish graduate education can leave students feeling quite isolated due in part to the lack of access to other graduate students, caused by the relatively small population of the country and hence the small size of its academic community.

- There is significant duplication of courses across the universities-for example, each department in each university may teach a course on research methods.

\subsection{Programme Structure}

The programme was designed to address each of the key issues outlined above. The LGSSE programme is unique in that it combines the best of the US and European $\mathrm{PhD}$ models. The $\mathrm{PhD}$ programme is four years in duration. The first year includes taught modules in research philosophies and methods as well as technical software engineering modules that support the students' research interests. During the first year of the programme, the student will prepare a research proposal for the 3-year research project. The taught component allows students to experience a more collegiate atmosphere among their classmates and reduce feelings of isolation. LGSSE will draw on the existing expertise of the four Lero partner Universities. The advantages include: 
- A leading-edge curriculum drawn from four of Ireland's leading universities.

- Access to a critical mass of world-class software researchers who form an expert advisory board for each student.

- Ability to leverage your research collaborations with leading research institutions and industry worldwide.

\subsection{Programme Challenges}

As with any collaborative project, a number of challenges have arisen. How does a non-academic institution like Lero (a research centre) award academic qualifications?

Essentially, Lero serves as a shop window for the four partner universities. Lero can offer short term internships to students while they are finalizing their research areas and looking for a supervisor. If a student enrolled in a particular university wishes to avail of modules at another university, how does this work? The logistics of taking a course remotely can be solved technically using podcasts or distance learning techniques. But how is the module credited? If the student enrolled in one institution, takes a module in another institution, what institution gives the credit? How can we normalize and make consistent the examination strategy and marking schemes across institutions? How are universities billed for making courses available remotely?

These are all complicated and complex questions that we are currently examining and plan to resolve.

\subsection{Programme Rollout}

After much planning and coordination among the 4 Lero partners, the LGSSE Programme Cycle began in September 2008 with 11 students enrolled. The students are from Ireland, Pakistan, Germany, England, Wales, and India. There has been significant interest in the LGSSE with over 155 applications received from 34 countries and 5 continents. Generous $\mathrm{PhD}$ studentships covering stipend, equipment and fees were awarded on a competitive basis for the first year of operation. The recruitment drive for September 2009 is currently underway and, at the time of writing, we are evaluating 168 applications from 39 countries and all continents (except Antarctica!). The establishment of LGSSE is a significant milestone in Irish software engineering graduate education.

\section{Lero Education and Outreach Programme}

Seventy per cent of Irish technology companies believe there is currently a very real and genuine skills shortage ${ }^{3}$. These companies are looking elsewhere to fill vacant positions. The Future Requirements for High-level ICT skills in the ICT Sector published by the Expert Group on Future Skills Needs at Forfas highlights the need to increase the supply of people with high-level ICT skills and "to reverse the recent decline in the domestic supply of high-level computing" graduates ${ }^{4}$.

The Lero Education and Outreach programme aims to instill an interest among students in computer science and programming at second-level. Career development

\footnotetext{
${ }^{3} \mathrm{http} / / / \mathrm{www}$. siliconrepublic.com/news/article/11494/randd/irelands-talent-meltdown

${ }^{4}$ http://www.forfas.ie/publications/forfas080623/egfsn080623_future_ict_skills.pdf
} 
literature highlights the value of experience as an important source of career development, as well as formal training [1,2]. Research reports that a hands-on component to the IT curriculum appears to facilitate IT career choice [2]. We have designed a programme that allows students to develop their own computer programs while at the same time learning fundamental computational concepts. These programs include games, animations and stories using a combination of graphics, photos, music and sound.

We want students to experience the enjoyable and engaging aspects of designing and building software. We want to introduce them to computational thinking [3] and present examples of Computer Science grand challenges in an accessible manner.

\subsection{Irish Secondary Schools}

The Irish secondary school cycle consists of a 3-year junior cycle, then an optional 1year transition year, followed by a 2-year senior cycle. At the end of the 3-year junior cycle, students take the Junior Certificate state examination. At the end of the 2-year senior cycle, students take the Leaving Certificate examination. During the final year at secondary school, students choose what they would like to study at university. A points system, based on grades in the state-run exams, determines which student gets access to which course in all of the Irish universities, institutes of higher education, and a handful of other institutions.

The Lero Education and Outreach Program is targeting the optional year between the junior and senior cycle: transition year. Transition year is unique in that it is an exam-free stress-free year and it "promotes the personal, social, vocational and educational development of students and prepares them for their role as autonomous, participative and responsible members of society"5. We feel it is the perfect time to introduce students to computational concepts and computational thinking. In designing an outreach programme for transition year students, a certain number of constraints needed to be considered. Sections 3.2, 3.3 and 3.4 outline these constraints.

It is worth noting that, currently, the European Computing Drivers Licence (ECDL) is being taught extensively in Irish secondary schools. This is a certificate that verifies competence in computer use. However, anecdotal evidence from teachers and students suggests this does little to inspire students and encourage an interest in the field of Computing or Computer Science.

\subsection{Technology Infrastructure in Irish Secondary Schools}

The technology infrastructure in Irish secondary schools is under-funded. Between 1998 and 2004 the Department of Education invested €157M in the ICT in Schools Programme, where technology infrastructure, skills infrastructure and support infrastructure were developed..$^{6}$ The planned investment of $€ 252 \mathrm{M}$ as part of the NDP 2007-2013 ICT in Schools Programme period has not materialized ${ }^{7}$. In comparison

\footnotetext{
${ }^{5}$ Transition Year Guidelines, 1994, Department of Education. http://ty.slss.ie/

${ }^{6} \mathrm{http}: / /$ www.ncte.ie/AbouttheNCTE/ICTPolicy/

${ }^{7}$ http://www.ndp.ie/documents/NDP2007-2013/NDP_Main_Ch09.pdf
} 
Northern Ireland receives $€ 75$ million annually, with approximately $1 / 3$ of the population of the Republic of Ireland. ${ }^{8}$

Many schools rely on fund raising to upgrade and maintain their computers and technology infrastructure. There is a wide range of technology infrastructure in Irish schools. A school may have a single computer laboratory with 30 computers running 2 or 3 different operating systems shared among 500-600 pupils. A school may have 3,4 or 5 computer labs running the latest operating systems shared among 500-600 pupils. Some schools employ and pay for technical support out of their core budgets. Some schools engage technical support services on a weekly basis for 2-3 hours per week. Some schools engage technical support services as required or as budgets allow. Some schools install wireless Internet connections. Other schools avail themselves of the broadband connection offered by the National Centre for Technology in Education (NCTE). The wide range of technology infrastructure set-up in Irish secondary schools needs to be considered when designing an outreach programme, especially one that will be rolled out at a national level.

\subsection{Skills Infrastructure in Irish Secondary Schools}

Currently there is no state exam in Computing or Computer Science at second-level in the Irish secondary school system. Four technology subjects (Architectural Technology, Design and Communications Graphics, Engineering Technology, and Technology) are on the curriculum and examined, but these do not involve a programming/Computer Science component. Generally teachers responsible for teaching "computers" at second-level are the mathematics, science or technology teachers. When designing an outreach programme, one needs to design something that is accessible to teachers that do not necessarily have a Computer Science background.

\subsection{Choosing a Software Tool for Teaching Computer Programming at Second-Level}

We evaluated a number of software tools that could be used to teach programming to second-level students. First we considered Greenfoot. This is a "combination between a framework for creating two-dimensional grid assignments in Java and an integrated development environment (class browser, editor, compiler, execution, etc.) suitable for novice programmers" 9 . Is it an excellent tool for teaching programming and freely available; but given the limitations of technology infrastructure in schools (a JVM generally requires more than 256MB of RAM) and lack of Java programmers amongst second-level computer teachers, the tool was deemed unsuitable for the Irish secondary school system.

Next we considered, and selected, Scratch as the software tool used to teach computational concepts. Scratch is a freely-available programming tool that was developed by the Lifelong Kindergarten group at the MIT Media Lab. It is very interactive, easy to run and install, even on 10-year-old machines, and allows students to create their first computer programs and games using a drag and drop easy-to-use interface.

\footnotetext{
${ }^{8}$ http://www.irishtimes.com/newspaper/ireland/2008/0807/1218047756866.html

${ }^{9}$ http://www.greenfoot.org/
} 


\subsection{Materials Developed}

It is vital to provide teachers with good support material that includes lots of illustrative examples. Taking the constraints above ( $\$ 3.2,3.3$ and 3.4) into consideration, during the summer of 2008, we designed a set of materials for schools, "Having Fun with Computer Programming and Games". Under the SFI STARs (Secondary Teaching Assistant Researchers) programme, we were fortunate to have two second-level ICT teachers work with us at Lero developing the materials. We developed a set of 10 modules with approximately 45 hours of teaching materials.

The materials teach computational concepts and computational thinking to students. The modules are designed so that an ICT/computer teacher provided with half a day of training is equipped to teach the materials to students. Students build computer games, create animations that use art and music, design and work in teams, test components of their games, modify and add new functionality to existing programs, present their projects to their classmates and provide feedback to their peers. The materials developed are available ${ }^{10}$ under a Creative Commons licence.

\subsubsection{Materials Described}

This section describes each of the modules in detail.

\section{Module 1: Getting Started}

The goal of Module 1 is to give students their first taste of programming and to engage them using Scratch. Module 1 contains five lessons. In the first lesson students discuss the impact of software on our lives. Lesson 2 introduces students to Scratch and they write their first computer program. Lesson 3 teaches students how to import and how to modify different characters in Scratch. In lesson 4, students are introduced to algorithms. Lesson 5 introduces event handlers.

\section{Module 2: Drawing Shapes and Repeating}

Module 2, which contains 3 lessons, covers algorithms and turtle graphics. Lesson 1 explores algorithms in more detail. Lesson 2 introduces iteration and the debugger. Students are asked to draw simple shapes, starting with a square, then triangles, pentagons and circles. Lesson 3 builds on lesson two and teaches nested loops.

\section{Module 3: Searching and Sorting}

Module 3 includes paper based activities and can be taught away from the computer. Module 3 covers searching and sorting, and contains 3 lessons. Lesson 1 introduces searching. This lesson uses materials developed for the Computer Science Unplugged project, http://csunplugged.org/. Students play a battleship game to learn about linear search, binary search and hash table search methods. Lesson 2 introduces the bubble sort, selection sort and quicksort methods. Students perform various sorting tasks and the efficiency of the different sorting mechanisms is discussed. Search engines and performing web searches are covered in Lesson 3.

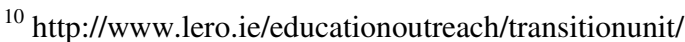




\section{Module 4: Build a Game}

In Module 4, students build a game. Module 4 contains 4 lessons. In lesson 1, students design a game on paper and implement their design in Scratch. Conditional statements are introduced in Lesson 1. In Lesson 2, students add more functionality to the game designed in Lesson 1. Variables are introduced in Lesson 2. Lesson 3 discusses images and image formats. Lesson 4 covers sound and sound formats.

\section{Module 5: Revision with Scratch Cards}

In Module 5, we want to make sure that all students have learnt and understood computational concepts taught so far. Module 5 contains three lessons. Different level Scratch cards - easy, difficult and extreme - are presented to students each containing a simple assignment. Each assignment revises concepts taught in the materials up to Module 5. When the assignments are completed, students can swap cards with their classmates until they complete all Scratch cards at each level.

\section{Module 6: Changing Things}

In Module 6, we want students to understand that code maintenance is very important and that writing software does not necessarily mean writing code from scratch. Module 6 contains two lessons in which students modify existing projects. They identify the part of the script that needs to be modified and program new or different behaviour.

\section{Module 7: Solving Complex Problems}

Module 7 introduces two complex computer science problems, The Towers of Hanoi and The Travelling Salesman Problem. The goal of this module is to introduce computational complexity to students in an accessible way. By playing the Towers of Hanoi, students should get a feel for how the complexity of the problem and the time required to solve the problem increases as the input or in this case the number of discs increases. Similarly, by playing a game to try and find the optimal route through a set of cities, students should get a feel for how the complexity of the problem and the time required to solve the problem for all possible routes increases as more cities are added.

\section{Module 8: Research Project}

Anecdotal evidence from teachers suggests that when students are asked to research a topic on the Internet, they generally search for the topic on Wikipedia, cut and paste the response and present this as the "answer" to the research topic. Module 8 attempts to address this problem. All research work is documented in a research worksheet and students are assessed using this worksheet at the end of the project. Students are required to present and answer questions on their research topic. Module 8 contains four lessons. In Lesson 1, students choose a topic of interest from a set of topics, all computing related and start working in teams. In Lesson 2, students spend time researching their topic of interest on the Internet. Lesson 3 teaches PowerPoint basics. In Lesson 4, all students present their research project and answer questions from their classmates and teacher. 


\section{Module 9: Advanced Game}

Students build an advanced game in Module 9. Module 9 contains four lessons. In Lesson 1, students build an advanced game. In Lesson 2, additional functionality is added to the game designed and implemented in Lesson 1. This includes adding variables and programming characters to behave in a certain way when they touch each other. In Lesson 3, additional functionality is added to the game built in Lesson 2. This includes enhancing the game play aspect of the game. In Lesson 4, students learn about software testing.

\section{Module 10: Scratch Project}

In Module 10 students combine their knowledge of computational concepts with their creative, artistic and musical ideas to create an original final project. Module 10 contains five lessons. In this module, students are divided into project teams, design and implement their final Scratch project.

\subsection{Pilot Project and Plan for National Rollout}

We are currently running a pilot project in a number of schools and we are planning to roll out the materials on a national scale starting in September 2009. In order to do this, we are building alliances and partnerships in Ireland so that we are a presenting a united front and adopting a coordinated approach with schools.

There are 730 second level schools in Ireland. Lero has formed partnerships with CIO Ireland and the Institute of Technology Tallaght (IT Tallaght). CIO Ireland are a group of senior ICT executives that

- Influence Government policy on ICT in Ireland;

- Promote ICT as an exciting career opportunity;

- Aim for a strong ICT entrepreneur and start-up environment in Ireland.

IT Tallaght have run a number of very successful Scratch workshops for transition year students. The Department of Education Transition Year Support Service are supporting our initiative. We will continue to build alliances with other organisations nationally over the next 12 months.

The pilot project is focused on rollout nationally. However, materials are freely available online to all registered users and we welcome increased participation. Currently over 130 people have registered for materials from 22 countries.

\section{Conclusions and Future Work}

Both educational initiatives are successfully up and running. The next step is to set up a process of evaluation so that we can track the effectiveness of the two educational endeavours initiated by Lero.

In four years, when the first graduates of LGSSE graduate, we will need to evaluate the outputs of the graduate students and the effectiveness of their research. For the Education and Outreach Programme, we will need to evaluate if students who have completed "Having Fun with Computer Programming and Games" have a more positive outlook on computer science and if the numbers taking computer science courses at third-level increases. This will involve working with teachers, guidance 
councillors, students etc., and putting something in place that will allow us to track students over time.

\section{Acknowledgements}

This work was supported, in part, by Science Foundation Ireland grant 03/CE2/I303_1 to Lero- the Irish Software Engineering Research Centre (www.lero.ie) and under the Higher Education Authority's Programme for Research in Third Level Institutions (PRTLI), Cycle 4, supported by the EU Structural Funds programme.

\section{References}

1. Lent, R.W., Brown, S.D., Talleyrand, R., McPartland, E.B., Davis, T., Chopra, S.B., Alexander, M.S., Suthankaran, V., Chai, C.M.: Career Barriers, Supports, and Coping Strategies: College Students' Experiences. Journal of Vocational Behavior, 61-72 (2002)

2. Joseph, D.: Increasing the Number of Entrants into the IT Profession: The Role of Experiential Training. In: Proceedings of the 2008 ACM SIGMIS CPR Conference, pp. 2-3 (2008)

3. Wing, J.: Computational Thinking. Communications of the ACM (2006)

4. Forfas: Future Requirements for High-Level ICT Skills in the ICT Sector (2008) 